\title{
Introduction
}

\section{Discursive cuts, receptive wounds: notes on the reception of Inxeba/}

The Wound

$>\quad$ Wemar Strydom

School of Languages, North-West University, Potchefstroom, South Africa

wemar.strydom@nwu.ac.za (preferred pronouns: he/him)

I Inxeba/The Wound

There is a specific strain of queer theory seeded in Southern African soil - a permutation that, for its specific geo-affective location, seems all the more lived, more humanisticcentred, more humane. The work collected in this themed issue arose from a panel discussion and a set of papers presented during the 2018 iteration of the February Lectures conference series (februarylectures.co.za), a platform established to showcase what happens when queer theory is brought to bear on the lived experience of queer peoples of the global South. In bringing together researcher-activists, artists, and academics - especially emerging academics - the conference series is one of a number of endeavours across Southern Africa aiming to break with entrenched epistemological privilege and fully embrace - for better or worse - the productive potentialities of queer theory with a decolonial agenda.

A few days before the conference, reports surfaced of the Film and Publication Board's (FPB) decision to apply an X18 rating to Inxeba - effectively banning the film from being shown in commercial venues after it had already enjoyed a limited, though critically well-received, run in art cinema theatres across the country. The presumed prohibition on public discourse around ulwaluko (a highly ritualised set of male initiation practices, which includes removal of the prepuce) was explicitly employed by a number of cultural groups to lobby the FPB to ban the film, and so fused discussions of the film with discussions of ulwaluko. 
The unprecedented public outpouring of vitriol - both for and against the film's banning - further inflamed tensions, while the manner in which ulwaluko was used point to a number of faultlines in South Africa's public sphere that test the tenacity of the citizenry's commitment to cultural-moral relativism.

Lungelo Manona and Andrea Hurst (in this issue) aptly show how the FPB's reasoning, that the film 'challenges the power base of traditional cultural leaders by opening the ulwaluko rites to general public scrutiny and comment', doesn't hold water; instead, as they point out, the "predominant reason for the outrage provoked by the film is that it depicts an entrenched cultural tradition in a way that subjects its heteronormative ideal of manliness to controversial critique from the perspective of more diverse, homosexual masculinities'.

The articles included in this issue engage with the notion of Inxeba as 'queer' on different levels - some hold it as emblematic of a queer oppositionality opening up in public discourse in South Africa, while others see a reductive identitarian turn in such oppositionality. Regardless (as I argue elsewhere in this issue), the film's reception re-opened discussional spaces on the role and function of film within the national consciousness, most of which centred around the representation of ulwaluko. The effective banning of the film, seen by many as an act of state-sponsored censorship, activated affective resonances in the collective memory of tactics of state apparatus of the pre-1994 SA government employed to first smear and then ban 'dissident' books, films, public meetings, and political activists.

As this issue went to print, the film's X18 rating had been overturned after a protracted legal battle launched by its production team; the articles collected here each deal overtly or indirectly - with the period of fraught reception between the act censorship and unbanning.

\section{Ulwaluko}

In speaking of Inxeba, thus, we also have to speak of ulwaluko. Whilst discussion of ulwaluko is held by many as prohibited in the public sphere - a prohibition much more ingrained in South Africa than similar proscriptions against discussing female genital mutilation (FGM) - scholarly work on the practice has been more forthcoming. Notably, Pumla Dineo Gqola's (2007) “'A Woman cannot marry a boy': Rescue, Spectacle and Transitional Xhosa Masculinities" frankly discusses the intersectional aspects of class, socio-economic status mobility, "tradition" and gendered injustice at play behind blanket injunctions on public discourse on ulwaluko. Similarly, in "'How boys become 
dogs': Stigmatisation and marginalisation of uninitiated Xhosa males in East London, South Africa", Mavundla, Netswera, Toth, Bottoman and Tenge (2010) show in detail how sexual de-socialisation and dehumanisation tropes are employed to harness affective modalities such as shame and pride in creating secrecy around the practice. In addition, a number of publications explore the way traditional circumcision practices intersect with, specifically, the lives of gay men in informal communities (Lynch \& Clayton 2016) and with gay men's HIV stigmatisation (Vincent 2008). Additionally, emblematic of work on gay Xhosa men's experiences around ulwaluko's validation of (heterosexual) cultural manhood is that of Ntozini and Ngqangweni (2016).

In a sense, responses to the film - which have rarely been neutral - echo the affectively textured landscape surrounding the practice: shame and humiliation if the initiate is found "wanting"; the viscerality of the experience; joy and elation at completing the ritual. Discussing the film and its reception, then, necessitates describing these affective experiences not in vague or abstracted terminology ("threshold experience"), nor (only) in subject-specific jargon ("liminality"), but in terms that activate the visceral materiality of the body's experience of the blade, the mountain air, the duskiness of the initiate's lodgings.

A number of articles in this issue describe and approach ukwaluko differently, attesting to the varied manner in which the practice is perceived. Gqola (2007:145) states that ulwaluko points to a series of interrelated practices, 'a complex initiation cluster that marks transition from young to more complex' masculinist identity, and as such reminds us of the need to complexify - not essentialise - the practice and its attendant cultural resonance(s).

Another way of confronting the effects of the practice is to visualise it, and here Mgcineni Sobopha's 2001 pictorial series Skins, scars, blankets and blood is a disquieting reminder of the viscerality of the practice - as is the mutilatory archive of ulwaluko.co.za. However, to my knowledge, no published work has yet looked at the representation of ulwaluko in narrative film. To this end, this issue brings together researchers from different disciplinary backgrounds and identity positionings to expand, through a consideration of the reception of Inxeba, on the ways in which ulwaluko can be understood.

\section{Overview of articles}

Bill Marshall positions the notion of queer cinema within larger, global narratives of activism, theory-making and reception, while simultaneously nuancing its functional applicability in 'world cinema' contexts. In Queer cinema and the global, Marshall 
casts a cultural-historical view on queer cinema's origins and, while conceding the inherent mobility of the concept, also questions the 'potential and pitfalls of deploying it with global or universal reach'.

If, however, the national is conceptualised in/through queer cinema as 'multiple horizons of belonging, as frameworks of space which speak to interconnecting and overlapping surfaces', then the focus shifts to a process of queering; this has the potential to productively surface 'the ways in which symbolic formations such as nations, ethnicities and diasporas are marked by hierarchical (hetero)sexual binaries whose normativities can be disrupted and undone, and realities reformulated and rewritten'.

A productive tension between local-global and colonial-post/decolonial manifests in a set of three articles that speak to the manner in which representational Afromasculinities can be read in Inxeba. In the first, an analysis informed by Lisa Downing's 'sex-critical' approach, Rory du Plessis reads the film as showcasing phallocentric scripting, wherein the sequencing and representational affect of sex scenes privilege the erect penis in the act of penetration. For du Plessis, this runs parallel to heteropatriarchal norms under contestation in the film - to counter this, the article incorporates Alphonso Lingis's writing on sexual desire to imagine alternative readings of the film's sex scenes.

By foregrounding pleasure that lies outside of penile penetrative sex, and so facilitating a move away from the phallocentric register of the film, du Plessis asks us to imagine 'convex and concave body parts, sexual desire, eroticism, lust and orgasmic arousal transform[ing] the physiological body to be a torrent of permutations, engorged protuberances and regions'; in essence, to imagine sex that is not wounding, but that goes some way toward a queer, more inclusive eroticism.

In Interrogating conceptions of manhood, sexuality and cultural identity, Siseko H Kumalo and Lindokuhle Gama conceive of manhood as a discursive tool, as a constantly-changing subjective understanding of self. In this view, masculinist identity is situated in a process of contested negotiation between two understandings of relational being (Manhood and manhood proper), brought to the fore when 'practiced and performed through broad social processes and solidified through and by social institutions, in this case the cultural practice of ulwaluko'.

In seeking to understand the moral panic accompanying the reception of Inxeba in South Africa, they predicate their argument on the interwoven nature of cultural identities, policed sexualities, and representational politics - all of which maintain the apparent fixities of masculinity. However, in acknowledging the functional necessity of aligning 
aesthetics with the ethical as a 'mode of attending to the deficiencies of Manhood', Kumalo and Gama purposely echo Pumla Dineo Gqola: only when we arrive at a processual understanding of cultural tradition - and its representation in popular culture - as constituting an acknowledgement of the deficiencies of masculinity, do we begin to understand how ritualised custom can heal (Gqola 2007:158) not (only) wound.

The final article on representational Afro-masculinities is On Oyèrónkẹ Oyèwùmí, colonial Afro-masculinities and the subjection of African cultural praxis in Inxeba, in which Rantsho A Moraka asks pertinent questions on the (in)commensurability of global North social schematic discourse on gender with Afro-cultural thought and conceptions of personhood.

Surfacing issues of (in)commensurability, the article situates an analysis of the film's representation of gendered identity in the work of Oyèrónkẹ Oyèwùmí, but simultaneously parallel to a Butlerian conception of gender performativity. As such, Moraka argues that contrary to seeing Inxeba as a 'gender progressive representation of African queer identity against a purportedly hetero-patriarchy African culture, [it] inadvertently reinscribes colonial gender grammars' into the rites of initiation.

The next set of three articles discuss, through differing methodological approaches, the extent to which colonial gender grammars are indeed entrenched in the film's tumultuous reception. In Layers of woundedness in Inxeba: masculinities disrupted, denied and defamed, Peace Kiguwa and Anele Siswana look comparatively at the multi-layered representations of aspects of Afro-masculinity in the film and in discourse around ulwaluko, and trace the role of heteronormativity in defining and engaging a critical, intersectional orientation toward practiced masculinities in contemporary South Africa. They hold that the film both fails and succeeds at representing the complexities of Afro-masculinity, and that the receptional furore around the film should be read within this success-failure at representation.

Kiguwa and Siswana consider aspects of heteronormativity in male rites of passage, as well as the affective economies of practice, shame, and fear that support and sustain heteronormativity. Significantly, they - and the majority of other contributors to this themed issue - signal that '[g]iven our engagement with issues of mis(representation) and analyses of masculinities as these appear in the film, it is perhaps useful to engage with our own self-location and politics'.

Likewise, Dylan Kukard and Richard van Rensburg, in Identity in interaction: subcultural intersubjectivities in popular radio conversation on Inxeba, interrogate their own subject positioning as researchers in exploring selected instances of radio discussion on 
issues of subjectivity raised by the reception of the film. They find that while radio hosts and callers navigate between a range of subject position alliances and strategies, 'the most potent is the discursive formation of queerness without direct invocation of this identity', such as through references to anal sex. 'What becomes apparent', they write, 'is that a particular knowledge around homosexuality has been produced by targeting the performance of anal sex as isolated to this group which is seen as an affront to other social positions'.

The fraught reception to Inxeba is infused by such examples of reductive binarism, and Kukard and Van Rensburg's article is a potent breakdown of the functional 'discursive individualisation of the queer body in the South African landscape, which is placed antagonistically against the 'collective tribe' [...where] [t]he discursive formation of the queer body as a-cultural, as sitting outside of the realm of traditional African culture, has been transferred into the local context' of the radio discussion under analysis here.

This tension between body and being, between act and belonging, is also surfaced in the third article on the film's reception, Lungelo Manona and Andrea Hurst's What is it to be a man? Rites, hashtags, outrage. In this contribution, the processes depicted in the film show the body as both a social construct and a perceived entity in the space 'beyond being a biological reality'. This speaks to more than just the duality between private and public, as, for the authors, '[o]f even more relevance to the film is the instance of the ritual being performed collectively'.

In attempting to affectively place the anger and outrage accompanying the film's reception, Manona and Hurst enter into a transnational dialogue between amaXhosa and Kurya, and consider inter alia the role pain (and public, masculinist-performative reaction to pain) plays within both sets of rituals. By factoring the performative nature of masculinities into the reception of the film, the article shows how modernisation and commercialisation of these rites have impacted not only the initiates' experience, but also the larger collective understanding of the socio-cultural functionality of such rites.

In addition to the academic contributions, two responsive pieces are brought together in this issue. The first of these is a response-review of Nakhane Touré's novel, Piggy Boy's Blues. As in his portrayal of the protagonist of Inxeba, Touré embodies the discreet disquiet of Xolani, and the actor's 2015 novel presages some of the thematic concerns of the film. It is in this light that Katlehiso Sixam re-reads the novel as a portent of the author's portrayal of Xolani. Sixam sees the novel as an embodied recollection of the past in order to account for the duality of understanding 'oneself as both a gendered being and a product of one's own ancestry'. Within this gender- 
culture duality, the unanswered - or unanswerable - call to take up a masculinity based on the past fills the novel's characters with nostalgia and a melancholy rendered as the titular 'blues'.

Sixam situates such a view - of masculinist expectation emanating from the past within larger narrative frameworks of protest and oppositional writing, stating that the novel 'purposes to traverse questions on gendered, lived experience and offers comfort and temporary relief from the burden of reading an overwhelming kind of literature in which one suffocates under its realist depiction of a nation's politics of lamentation and/or protest [...]'.

The second response piece, by S'nothile Gumede, is a deeply resonant reply to the overall project emblemised by the articles collected together here. The somewhat enigmatic title, 2018, Still struggling with a pair of shoes bought in 1996?, can be taken to refer to the specific, nuanced ways in which academic endeavours respond to the societal project of national building - recognising that while 'culture and tradition dismiss alternative discursive horizons with the intention of binding society into a rigid system of heteronormative hegemony', we can still 'sculpt alternative realities into existence, through literature, art and film'.

Such a clarion call goes out not only to those versed in the artistry and technicalities of filmmaking, but also to those of an academic bent. In asking '[h]ow then do we reconcile culture, tradition and queerness?', Gumede riffs on Mbembe and Foucault, quotes Karl Popper and references Zanele Muholi, thereby showing integrated possibilities for breaking out of normative bindings - and so situates the piece as a coda of sorts to the collected work preceding it.

\section{Lexical notes}

Within a queer theoretical framework, which challenges essentialised and essentialising terminology, contributors were advised against using totalising terms, such as 'African', when more specific and scoped terminology would better suit the argument. Specifically in terms of ulwaluko: as the work of Finlayson (1998) attests, there are linguistic implications both inherent to the practice of ulwaluko and to discourse constructed around it. Most of the work in this issue, for example, situates the practice between ritual and rite. The connotative and denotative range of terms such as ritual, rite, wounding, etc. was left to each individual contributor to delineate. 
While a number of scholars were consulted on this issue, issue-wide stylistic and textual considerations are indicative of my own subjective worldview: the use of ulwaluko without quotations marks, but italicised; the use of amaKhoza instead of 'Khoza nation'/'Khoza peoples', and so forth. These textual decisions were made with a view to balance the needs of an international readership - who might be unfamiliar with the connotative weight certain terms carry - with a wariness of representing linguistic terms as exotic lexicalities (especially in work that borders on cultural anthropology, a field where the affective echoes of colonialist language use still linger).

There is indeed a decolonial lexical implication to be read in the titular slash between 'Inxeba' and 'The Wound'; something hovers in the doubling of 'Wound/The Wound' that not only implies a cultural and linguistic differentiation, but also a possible disjunct. What can be (is allowed to be) translated? What echoes across the disjunct implied by the dash? What responsibilities (if any) do we have to address this disjunct?

\section{Subject positioning of the scholar within a decolonial frame}

Eschewing the perceived prohibition on public discourse around the practice of ulwaluko, this issue brings together various voices and viewpoints that co-construct a snapshot of both critical and popular response to the film - some speaking to the practice of ulwaluko from within the parameters of a cultural identity that practices initiation rites, others from cultural positions that do not.

As Dylan Kukard and Richard van Rensburg (in this issue) remind us, in a frank discussion of the intersection between method, data, and self-identity, 'interpretative choices can have political effects'. This awareness runs clearly through most of the contributions to the issue, and is evident of a much-needed turn in decolonial discourse toward extended awareness of - and openness about - the scholarly subject position.

Whilst it is redundant - but perhaps unavoidable - to comment on the necessity and importance of including various viewpoints, in many ways, the furore over Inxeba is also emblematic of academic fault-lines unaddressed (or, in some regards, overaddressed) since 1994. The willingness of emerging academics to surface the role that subject positioning plays in their work stands in converse relation to the relative hesitance of more established scholars working on Xhosa representation in popular media to contribute to this issue and to critical discourse around the film's reception. Notwithstanding, read together, these articles co-construct a cogent and encouraging 
example of how an emerging generation of South African scholars has started coming into their own, aware of the need for navigating and qualifying Eurocentric frameworks while simultaneously avoiding the lure of a narrow brand of decoloniality that thrives on reductionist Western/African binarism.

\section{REFERENCES}

Anon. 2018. Complications. [O] Available: https://ulwaluko.co.za/ Accessed 10 October 2018.

Finlayson, F. 1998. The Linguistic implications of the Xhosa initiation schools. Language Matters 29(1):101-116.

Gqola, PD. 2007. 'A woman cannot marry a boy': Rescue, spectacle and transitional Xhosa masculinities, in From boys to men: social constructions of masculinity in contemporary society, edited by T Shefer, K Ratele, A Strebel, N Shabalala \& R Buikema. Lansdowne: UCT Press:145-159.

Lynch, I \& Clayton, M. 2016. 'We go to the bush to prove that we are also men': traditional circumcision and masculinity in the accounts of men who have sex with men in township communities in South Africa. Culture Health \& Sexuality 19(3):279-292.

Mavundla, T, Netswera, F, Toth, B, Bottoman, B \& Tenge, S. 2010. 'How boys become dogs': stigmatization and marginalization of uninitiated Xhosa males in East London, South Africa. Qualitative Health Research 20(7):931-941.

Ntozini, A \& Ngqangweni, H. 2016. Gay Xhosa men's experiences of ulwaluko (traditional male initiation). Culture, Health \& Sexuality 18(11):1309-1318.

Shefer, T, Ratele, R, Strebel, A, Shabalala, N \& Buikema, R (eds). 2007. From boys to men: Social constructions of masculinity in contemporary society. Lansdowne: UCT Press.

Sobopha, M. 2001. Skins, scars, blankets and blood: a pictorial response to the tensions and conflicts that arise from the representation and the practice of ulwaluko in contemporary South Africa. Materials submitted for MFA, University of Cape Town, Cape Town.

Vincent, L. 2008. 'Boys Will Be Boys': Traditional Xhosa male circumcision, HIV and sexual socialisation in contemporary South Africa. Culture, Health \& Sexuality 10(5):431-446. 